\title{
A!
}

This is an electronic reprint of the original article.

This reprint may differ from the original in pagination and typographic detail.

Mannila, Linda; Nordén, Lars Åke; Pears, Arnold

\section{Digital competence, teacher self-efficacy and training needs}

Published in:

ICER 2018 - Proceedings of the 2018 ACM Conference on International Computing Education Research

DOI:

$10.1145 / 3230977.3230993$

Published: 08/08/2018

Document Version

Publisher's PDF, also known as Version of record

Published under the following license:

Unspecified

Please cite the original version:

Mannila, L., Nordén, L. A., \& Pears, A. (2018). Digital competence, teacher self-efficacy and training needs. In ICER 2018 - Proceedings of the 2018 ACM Conference on International Computing Education Research (pp. 78-85). ACM. https://doi.org/10.1145/3230977.3230993

This material is protected by copyright and other intellectual property rights, and duplication or sale of all or part of any of the repository collections is not permitted, except that material may be duplicated by you for your research use or educational purposes in electronic or print form. You must obtain permission for any other use. Electronic or print copies may not be offered, whether for sale or otherwise to anyone who is not an authorised user. 


\section{Digital Competence, Teacher Self-Efficacy and Training Needs}

\author{
Linda Mannila \\ Aalto Univ. \& Linköping Univ. \\ Espoo, Finland \& Linköping, Sweden \\ linda.mannila@aalto.fi
}

\author{
Lars-Åke Nordén \\ Uppsala University \\ Uppsala, Sweden \\ lars-ake.norden@it.uu.se
}

\author{
Arnold Pears \\ Uppsala University \\ Uppsala, Sweden \\ arnold.pears@it.uu.se
}

\begin{abstract}
Computing related content is introduced in school curricula all over the world, placing new requirements on school teachers and their knowledge. Little attention has been paid to fostering the skills and attitudes required to teach the new content. This involves not only traditional computing topics, such as algorithms or programming, but also the role of technology in society as well as questions related to ethics, safety and integrity. As technology develops at a fast rate, so does the content to be taught. Learning computing content through isolated in-service training initiatives is by no means enough, but rather, teachers need to develop confidence to independently and continuously explore what is new, what is relevant and how to include digital competence in their teaching. Teachers' self-efficacy is hence of crucial importance.

In a previous article [13] we described the development of a self-efficacy scale for teachers, focusing on digital competence as described in EU's framework DigComp 2.0. In this paper, we extend that work by analysing 530 teachers' responses collected in Autumn 2017 during a series of workshops and other professional development events. Our goal was to collect baseline data, painting a picture of teachers' current self-efficacy levels in order to facilitate follow-up studies. In addition, our results also point out challenging areas, consequently providing important insight into what topics and themes should be emphasized in professional development initiatives.
\end{abstract}

\section{KEYWORDS}

Digital competence, self-efficacy, teacher training, K-9 education, professional development

\section{ACM Reference Format:}

Linda Mannila, Lars-Åke Nordén, and Arnold Pears. 2018. Digital Competence, Teacher Self-Efficacy and Training Needs. In ICER '18: 2018 International Computing Education Research Conference, August 13-15, 2018, Espoo, Finland. ACM, New York, NY, USA, 8 pages. https://doi.org/10.1145/3230977. 3230993

\section{INTRODUCTION}

As computing related topics are introduced in school curricula a range of new challenges arise. While teaching and learning computing content at university level has been the focus of research

Permission to make digital or hard copies of all or part of this work for personal or classroom use is granted without fee provided that copies are not made or distributed for profit or commercial advantage and that copies bear this notice and the full citation on the first page. Copyrights for components of this work owned by others than ACM must be honored. Abstracting with credit is permitted. To copy otherwise, or republish, to post on servers or to redistribute to lists, requires prior specific permission and/or a fee. Request permissions from permissions@acm.org.

ICER '18, August 13-15, 2018, Espoo, Finland

(C) 2018 Association for Computing Machinery.

ACM ISBN 978-1-4503-5628-2/18/08 ..\$15.00

https://doi.org/10.1145/3230977.3230993 for quite some time, most questions still need to be formulated and empirically studied in primary and high school education. One of the most important questions concerns teacher preparation; how can teachers prepare for teaching the new content and integrate computing and digital competences in different subjects into their everyday classroom practice. As technology develops rapidly, so does the content to be taught. Learning new content through isolated in-service training initiatives is not sufficient, rather, teachers need to develop the confidence to independently and continuously explore what is new, what is relevant and develop methods through which they can include digital competence in their teaching [14].

Teacher self-efficacy is a key factor in this process, as it is strongly correlated to an individual's perseverance and resilience in the face of difficulty. A low self-efficacy is more likely to result in lower levels of persistence, and ultimately failure to deal effectively with the task at hand. The higher the sense of efficacy, the greater the effort, persistence, and resilience of the individual [7, 22]. These are factors that are crucial to problem solving endeavours in computing, self-regulated learning, and lifelong learning. There are also studies indicating that teachers with high self-efficacy positively affect student learning and building of new competences [11, 17, 19]. These arguments underpin the important contribution strong self-efficacy in digital competences can make, and emphasise its necessity in supporting teachers as they start to involve themselves in an evolving curricula that include computing and digital competences.

In [13] we described the development of a self-efficacy scale for teachers, focusing on digital competence as described in the European Commission's DigComp 2.0 framework. DigComp is highly influential and affects how computing and digital competences are viewed in national school curricula within the European Union (EU). For instance, revised curricula in Sweden and Finland have seen the introduction of digital competence as a transverse collection of knowledge and skills. The Finnish curriculum came into force in fall 2016, while the Swedish revisions will take effect in July 2018. The DigComp standard can however also be considered relevant to countries outside the EU. The items included in our instrument are directly derived from the key dimensions of the DigiComp framework.

In this paper, we extend our previous work by analysing responses collected from 530 teachers in Autumn 2017 during a series of workshops and professional development events. In a situation like this one, where an entire profession is affected, it is important - both for individual teachers and for decision makers - to be able to evaluate and follow-up on competence levels over time. For this we need both a suitable instrument and comparison data. The goal of this study was therefore to provide data that can be used as a basis for future studies. The results describe teachers' current digital competences and self efficacy. We also identify challenging areas, consequently providing important insight into what topics 
Table 1: Listing of competences included in the DigComp 2.0 framework.

\begin{tabular}{ll}
\hline Competence area & Competence \\
\hline \multirow{3}{*}{ Information and data literacy } & 1.1 Browsing, searching and filtering data, information and digital content \\
& 1.2 Evaluating data, information and digital content \\
& 1.3 Managing data, information and digital content \\
\hline & 2.1 Interacting through digital technologies \\
& 2.2 Sharing through digital technologies \\
& 2.3 Engaging in citizenship through digital technologies \\
& 2.4 Collaborating through digital technologies \\
Communication and collaboration & 2.5 Netiquette \\
& 2.6 Managing digital identity \\
& 3.1 Developing digital content \\
& 3.2 Integrating and re-elaborating digital content \\
& 3.3 Copyright and licenses \\
& 3.4 Programming \\
\hline Digital content creation & 4.1 Protecting devices \\
& 4.2 Protecting personal data and privacy \\
& 4.3 Protecting health and well-being \\
& 4.4 Protecting the environment \\
\hline Safety & 5.1 Solving technical problems \\
5.2 Identifying needs and technological responses & 5.3 Creatively using digital technologies \\
5.4 Identifying digital competence gaps \\
\hline
\end{tabular}

and themes should be emphasized in professional development initiatives.

The study focuses on two main questions:

- What is the current level of teachers' self-efficacy in digital competence?

- What areas need to be emphasized in teacher training efforts?

The paper is organized as follows. We begin by briefly describing the theory underlying the notion of self-efficacy. Next we present the DigComp framework and our self-efficacy instrument. We then present the study setting and methodology, and provide the details of our results. We conclude the paper with a discussion of these results and their implications for in-service and pre-service teacher training.

\section{THE DIGCOMP FRAMEWORK}

The European Commission defines digital competence in terms of five main competence areas in their framework DigComp 2.0. These competence areas are: 1) information and data literacy, 2) communication and collaboration, 3) digital content creation, 4) safety and 5) problem solving. Each competence area is accompanied by 3-6 competences, describing the skills and knowledge seen as essential for the component at hand (Table 1) [4].

\section{SELF-EFFICACY}

Self-efficacy theory is used in educational research, training and other activities where a person is to attain a new, or develop a higher, level of skill. Self-efficacy is defined as a belief in personal agency, for instance one's ability to successfully perform a particular behaviour or task [6]. Bandura discusses self-efficacy in terms of belief in one's capabilities to organize and execute the course of action required to attain a goal [2]. Self-efficacy beliefs exert a palpable influence on behaviour, in particular how long individuals persevere when confronted with difficult tasks and how resilient they will be in the face of difficulty or failure. A low self-efficacy is more likely to result in less persistent efforts in relation to a task, and may ultimately result in failure to complete the task at hand. Attainment of a high sense of self-efficacy is at least as important as possessing the skills themselves. Studies have shown that a person that lacks a certain skill still can complete a task requiring that skill successfully if their self-efficacy regarding the skill is high. Self-efficacy beliefs are also malleable and can affect a person's intellectual performance.

Research on teacher self-efficacy identifies a positive correlation between teacher self-efficacy and students' motivation, achievements and building of competences [11, 17, 19, 24]. Teacher selfefficacy also affects students indirectly via the instructional strategies, planning and a willingness to try out new material and approaches to teaching a subject [20]. Teacher self-efficacy seems to 
be a rather strong predictor of the way teachers shape their teaching practices in order to foster students' motivation to learn [19] and is thus relevant in education as well as other activities where skill development is a primary focus [16].

The perceived self-efficacy of an individual refers to an identified strength [7] which is measured by degrees of certainty that one can perform specific tasks [27]. As a consequence, self-efficacy is typically measured directly by the subject of the study using a selfreporting scale. Preparation of a self-efficacy scale that properly measures the behaviour in question requires careful design.

A self-efficacy scale consists of a number of statements (items) that express a personal position in relation to different skills and competences related to the subject in question. Respondents are asked to express to what extent they believe that they could do what is described in the statement based on their current level of knowledge. Answers are recorded on a Likert scale. Statements are positively-worded and express actions rather than expressing specific knowledge. In the case of testing whether a person knows how to turn on a computer, an appropriate statement in a selfefficacy scale might be I could turn on a computer rather than I know how to turn on a computer.

\section{SELF-EFFICACY IN DIGITAL COMPETENCES}

As we observed in the previous section, there is an extensive body of literature on self-efficacy $[1,10,26]$. However, this literature, while providing a scholarly foundation for our work, is not sufficiently specific as to be directly applicable to the evaluation of self-efficacy in relation to the teaching of digital competences.

Several self-efficacy scales have been developed for computing skills and sub-areas of digital competence, e.g. [3, 5, 12, 15, 21, 25]. While relevant, these scales focus primarily on core computing skills, in contrast to the broader set of skills that DigComp identifies. In [13] we developed a scale aimed at evaluating the self-efficacy of practising school teachers in the context of computing and/or digital competence being added to national school curricula in Europe. The approach being taken by European national authorities affects not only teachers in programming and computing, but also in many other school subjects including mathematics, natural sciences, technology and craft.

As a first step in deriving a self-efficacy scale, we created a list of 74 statements to cover the competence areas and competences specified in DigComp 2.0. The majority of the statements were directly inspired by examples provided by the framework. In addition to the items we extracted from the framework documents we formulated a small number of additional statements to provide specific coverage of competences and knowledge that our prior research and development work has identified are relevant for school teachers. The 74-statement scale was converted into an online questionnaire, where teachers were asked to rate their own confidence in relation to each of the 74 statements on a scale of 1 (very uncertain) to 7 (very confident). In addition, we asked some background questions related to their teaching background and subjects. The scale was distributed online to teachers and school leaders in Finland and Sweden using a combination of social media, mailing lists and group communication tools. The questionnaire was administered in Swedish. Given that the curriculum content related to digital competence is rather similar in Finland and Sweden, these two countries they seemed a natural choice for our pilot study. In addition, there are Swedish speaking teachers in both countries, making it possible to avoid potential ambiguity arising from a need to translate the statements into several languages. Based on 107 responses the 74 items were reduced to 27 statements through removal of redundant items as well as items with poor discriminatory power. This was done by computing discrimination indexes for all items and performing cross correlation between all responses. A more detailed description of the process of developing the instrument can be found in [13].

\section{METHODOLOGY}

\subsection{Data collection}

The data were collected using the 27-statement instrument during professional development initiatives in Sweden during a threemonth period (September - November) in 2017. The workshops were 1-3 hours long and discussed digital competence from a school perspective building on the questions why, what and how: why is this area introduced in the curriculum, what does it mean in practice and how can the new content be taught? The workshops were interactive and the participants were expected to share ideas and experiences with each other. As Sweden is only about to renew their curriculum it is likely that most respondents had not participated in any large scale professional development programs before attending the workshops.

The instrument was distributed as an online questionnaire during workshops and seminars, giving the respondents the opportunity to ask questions and discuss the instrument right after filling it out. No discussions took place while the respondents answered the questionnaire, and no changes were made to the responses once submitted.

Just as when developing the instrument, we used a 7-point Likert scale when asking respondents to rate the 27 statements based on how certain they felt that they could carry out the activity described in each statement. The response options ranged from 1 (very uncertain) to 7 (very confident).

In addition to the 27 statements, the instrument also asked for background information (years of teaching, experience of technology in teaching, age, gender, grade levels taught, subjects taught, comments on the statements).

The respondents were in one way or another involved in teaching at kindergarten or primary school (grades 1-9) in Sweden. All in all we received 530 responses $(80.6 \%$ female, $16.0 \%$ male, $3.4 \%$ would rather not say). Almost $80 \%$ of the respondents were teachers, whereas the rest were either principals or had a specific area of expertise (for instance, IT, extracurricular activities or special education). Over a fifth (22\%) of the teachers had less than 5 years of teaching experience, $39 \%$ had taught for 5-15 years, $26 \%$ for $16-25$ years and $13 \%$ had more than 25 years of teaching experience.

The largest age group was those reporting to be $40-49$ years of age $(31.5 \%)$. Roughly one fifth of the respondents were aged under 30 years (16.8\%), 30 - 39 years $(21.3 \%)$ and 50 - 59 years $(22.3$ $\%)$. Only $6.0 \%$ were over 59 years old, while $2.1 \%$ did not want to state their age. Technology use varied greatly, as some respondents 
stated that they used no technology at all, whereas others listed a long set of tools and approaches for integrating technology in the classroom.

\subsection{Analysis}

Responses were collected using an online form, from which the data were downloaded for statistical analysis. Self-efficacy scores were summed for each respondent across the 27 instrument and the sum was mapped onto the scale 1-7. In this way a composite self-efficacy measure (CSE) was created, making it possible to compare the overall self-efficacy scores of the respondents. The corresponding analysis was also conducted for each competence area separately, in order to make it possible to compare teachers' CSE for the five areas. In addition, we also summed the scores for each of the 27 statements, in order to gain insight into the experienced difficulty level of individual competences. By creating a composite measure, the data were transformed from ordinal into quantitative, making it possible to also calculate descriptive statistics such as medians, means and standard deviations.

In a situation where professional development initiatives are discussed and planned, it is important to have insight into what the actual needs are. To address this question, we describe three general CSE levels (low, moderate and strong self-efficacy) in order to paint a picture of the broad and diverse need for training efforts. A CSE of 1-3 was decided to represent low self-efficacy, 4-5 moderate self-efficacy and 6-7 strong self-efficacy.

Each of the 27 competences in the test relate to one of the competence areas presented in table 1 . The cumulative distribution for each competence area was computed to describe differences in distributions of perceived self efficacy for each area.

\section{RESULTS}

The composite self-efficacy (CSE) scores can be analysed both on a respondent and a statement basis. When treating the data on a respondent basis we computed a cumulative self-efficacy for the individual by summing the scale values for all items in the instrument. In this case, the lowest possible summed self-efficacy was 27 and the highest possible 189 (27 statements with minimum score 1 and maximum score 7). When conducting the corresponding analysis for individual scale items considering the entire population of respondents, the lowest possible summed score was 530 and the highest possible 3710 (530 responses with minimum score 1 and maximum score 7).

\subsection{Respondent CSE scores}

Individuals with a summed score of 27 points (corresponding to 1 on all statements) were categorized as a CSE of 1, those with a score in the range 28-54 were categorized as a CSE of 2, and so forth.

For our sample the mean overall CSE for all respondents was 4.65 , with a standard deviation of 1.22 . The median CSE was 5 . The distribution of CSE scores among the 530 respondents is presented in Figure 1.

When conducting the corresponding analysis separately for the five competence areas, we arrived at scores between 5-35 (for areas with five statements) and 6-42 (for areas with six statements). For areas with five statements a CSE of 1 consequently corresponded to

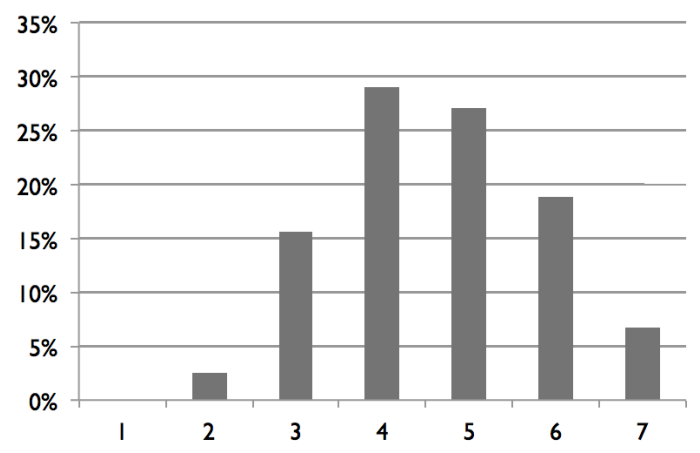

Figure 1: Distribution of CSE (1-7) among the 530 respondents

a summed up score of 5, a CSE of 2 to a summed up score between 6-10, and so on. For areas with six statements, on the other hand, a CSE of 1 corresponded to a summed up score of 6 , a CSE of 2 to a summed up score between 7-12, and so forth. The CDF plot in Figure 2 illustrates the distribution of CSE scores for the five competence areas (CA1..CA5) respectively.

As the diagram illustrates, teachers' CSE score is the highest (mostly 5 and 6) for the first competence area (CA1: Information and data literacy), while the lowest CSE scores are found in the third competence area (CA3: Digital content creation).

\subsection{CSE scores for individual competences}

Analysis of competence components is based on the cumulative value attributed to the scale statements by the 530 respondents. After sorting the statements according to their score and then categorizing them onto the scale 1-7 (CSE $1=$ score 530, CSE 2 $=$ scores in the range 531-1060, and so on), we obtained the results shown in the column "Overall CSE" in Table 2.

The mean overall CSE for all statements is 4.59 with a standard deviation of 0.80 . The median is 5 . None of the individual statements or competences has one of the lowest (1-2) or highest (7) CSE scores. The specific competences with the highest overall CSE score (6) are related to using search engines, storing and organizing digital content and recognizing hate speech online. Correspondingly, the competences with lowest self-efficacy (3) are choosing a suitable creative commons licence and writing a program that accomplishes a certain task.

The distribution of CSE scores for each of the competence areas is shown in Figure 2. We observe a substantial difference between the first and the third competence areas, represented by the top and bottom curves in Figure 2. A closer look at competence area 3 is presented in Figure 3, in which the competences labelled C1..C6 correspond to the 6 competences in competence area 3 presented in Table 2. This closer examination reveals, for instance, that over $60 \%$ of all respondents had a weak CSE (1-3) on the statement "I could write a program that accomplishes a certain task provided I had sufficient time".

In addition to looking at the overall CSE scores, we also analysed the scores based on the CSE level (low, moderate or strong). A low self-efficacy is defined as an overall CSE of 1,2 or 3 , and was the 


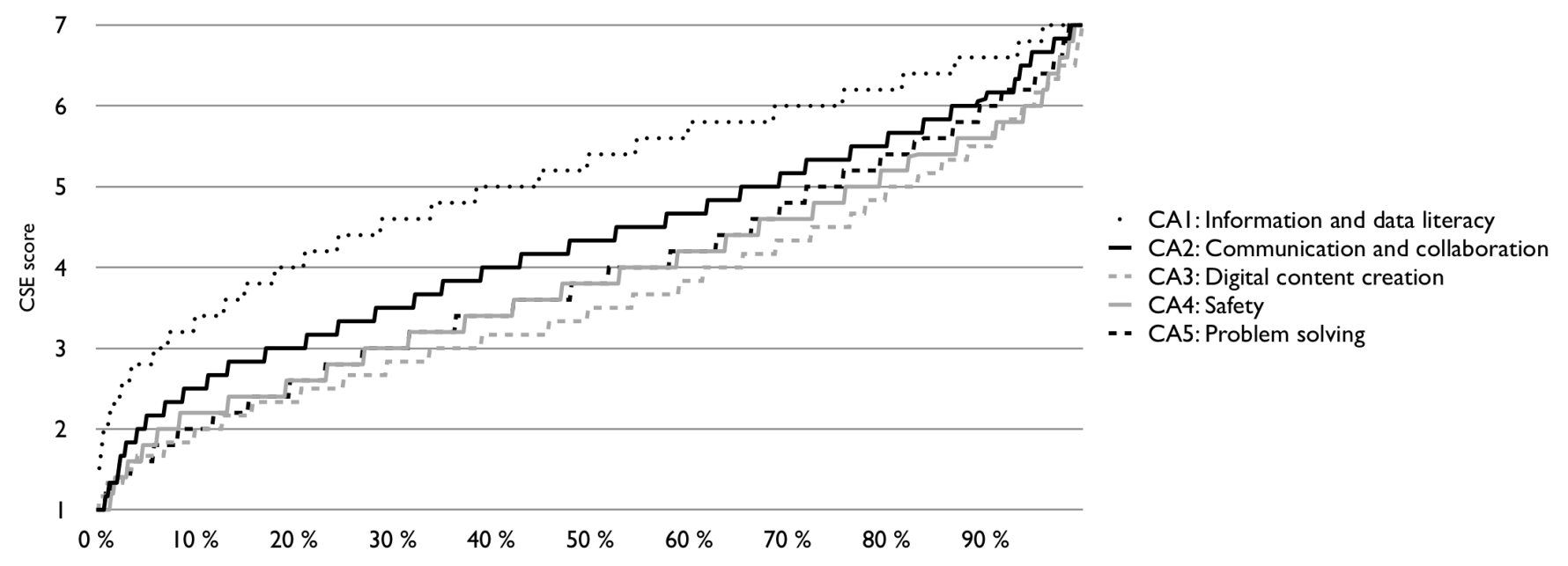

Figure 2: CDF plot showing the CSE score distribution (1-7) among the 530 respondents and the five competence areas

Table 2: CSE of individual competences

\begin{tabular}{|c|c|c|c|c|c|}
\hline Competence area & I could... & $\begin{array}{l}\text { Overall } \\
\text { CSE }\end{array}$ & $\begin{array}{l}\text { Low } \\
\text { CSE }\end{array}$ & $\begin{array}{l}\text { Mod. } \\
\text { CSE }\end{array}$ & $\begin{array}{l}\text { Strong } \\
\text { CSE }\end{array}$ \\
\hline \multirow{5}{*}{$\begin{array}{l}\text { Information } \\
\text { and data } \\
\text { literacy }\end{array}$} & ... adapt my searches based on knowledge about how search engines produce results & \begin{tabular}{l|l}
5 &
\end{tabular} & 4 & 5 & 7 \\
\hline & ... use search engines to find a given type of information, e.g. images, videos or maps & 6 & 5 & 6 & 7 \\
\hline & ... determine whether a news story being disseminated online is false & 5 & 4 & 5 & 6 \\
\hline & ... store and organize digital content in a way so I can later find it & 6 & 4 & 6 & 7 \\
\hline & ... choose a safe and lasting storage place for digital content & 5 & 4 & 5 & 7 \\
\hline \multirow{6}{*}{$\begin{array}{l}\text { Communication } \\
\text { and collabo- } \\
\text { ration }\end{array}$} & ... communicate with someone online without exposing my identity & 4 & 2 & 4 & 6 \\
\hline & ... correctly cite the creator when using or disseminating other people's material & 5 & 3 & 4 & 6 \\
\hline & ... find a relevant online meeting place for a specific area of interest & 5 & 3 & 5 & 7 \\
\hline & ... arrange an online meeting as a replacement for a physical meeting & 5 & 3 & 5 & 7 \\
\hline & ... recognize hate speech in discussions online & 6 & 4 & 6 & 7 \\
\hline & ... manage and delete my digital traces & 4 & 2 & 3 & 5 \\
\hline \multirow{6}{*}{$\begin{array}{l}\text { Digital } \\
\text { content } \\
\text { creation }\end{array}$} & ... combine tools in order to create digital content & 5 & 3 & 5 & 7 \\
\hline & ... summarize information from different sources in a representative manner & 5 & 4 & 5 & 7 \\
\hline & ... choose a suitable creative commons license for material I have created & 3 & 2 & 3 & 5 \\
\hline & ... write a program that accomplishes a certain task provided I had sufficient time & 3 & 2 & 3 & 5 \\
\hline & ... plan and design a solution to a problem in the form of step-by-step instructions & 4 & 2 & 4 & 6 \\
\hline & ... identify when and how programming can be used in different subject areas & 4 & 2 & 3 & 5 \\
\hline \multirow{5}{*}{ Safety } & ... protect digital equipment from undesired access online & 4 & 2 & 3 & 5 \\
\hline & ... detect when someone is trying to trick me into sharing personal information & 5 & 3 & 5 & 6 \\
\hline & ... identify web sites that can be used for fraud or other types of unwanted activity & 4 & 3 & 4 & 6 \\
\hline & $\ldots$ help prevent online bullying & 5 & 3 & 4 & 6 \\
\hline & ... estimate the impact of my use of digital equipment on the environment & 4 & 3 & 4 & 6 \\
\hline \multirow{5}{*}{ Problem solving } & ... find solutions to technical problems by searching online & 5 & 3 & 5 & 7 \\
\hline & ... adapt and adjust the behaviour and functionality of a program through its settings & 4 & 2 & 4 & 6 \\
\hline & ... construct a product with the support of digital technology & 4 & 2 & 3 & 6 \\
\hline & ... learn a new programming language on my own & 4 & 2 & 3 & 5 \\
\hline & ... adapt my ways of working based on new digital tools & 5 & 3 & 5 & 7 \\
\hline
\end{tabular}




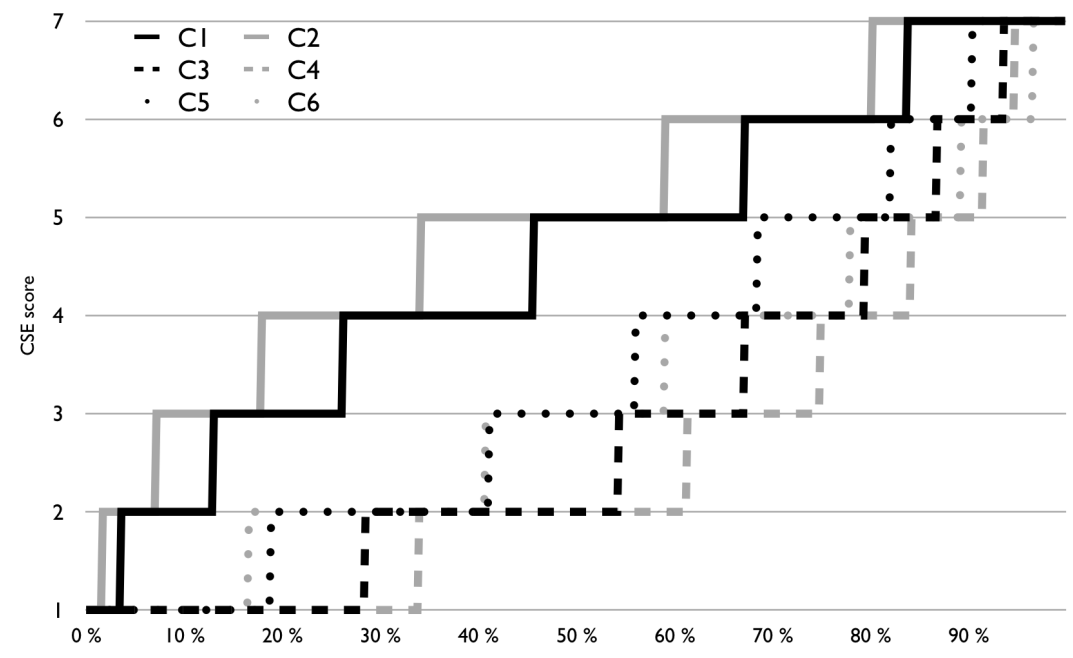

Figure 3: CDF plot of the CSE scores for the individual statements in competence area 3 (Digital content creation)

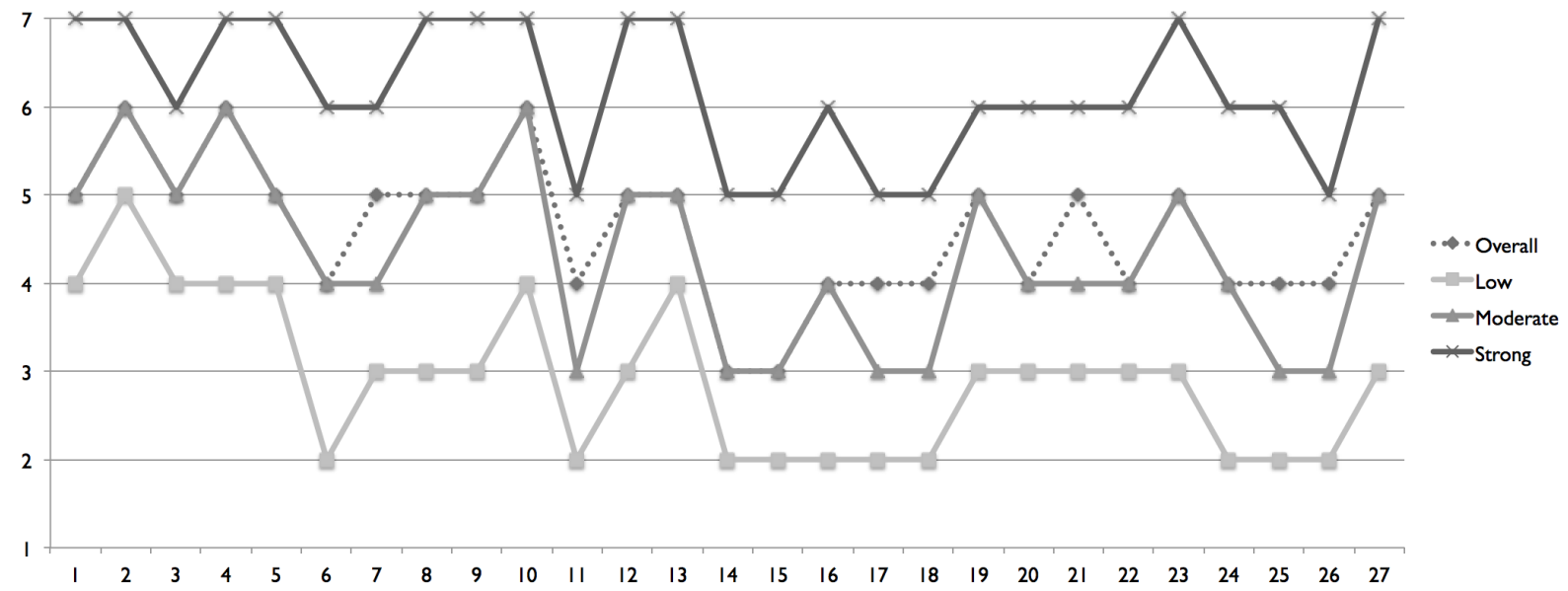

Figure 4: CSE scores plotted for the 27 individual statements

result for $18 \%$ of the respondents (Figure 1). These cases had a mean CSE of 2.86 and a standard deviation of 0.34 . No teacher had the lowest CSE score (1). Over half (56\%) of the teachers exhibited a moderate self-efficacy, that is, an overall CSE of 4-5, with a mean CSE of 4.48 and a standard deviation of 0.50. Finally, a strong selfefficacy is defined as a CSE of 6-7. In our study, $26 \%$ of the teachers ended up at this CSE level. These cases had a mean CSE of 6.26 and a standard deviation of 0.44 .

The three columns to the right in Table 2 show the corresponding CSE score for each statement and CSE level. Similarly, the diagram in Figure 4 visualizes the differences in CSE scores between the three levels and the overall result for the 27 statements. The results pinpoint large differences overall for most statements. The gap between a low and strong self-efficacy score is the largest for statement 6 ("I could communicate with someone online without exposing my identity") and smallest for the first competence area (Information and data literacy, statements 1-5).

\section{DISCUSSION}

The results presented above show a large spread in teachers' selfefficacy levels. The competences with the highest overall CSE were those in competence area 1, that is, skills related to information and data literacy. This finding is in line with our pilot study when developing the self-efficacy instrument [13], where we found that the respondents, in general, felt most confident in this area. This can, however, be considered an expected result, as handling data and information is something we all do on a regular basis in our everyday life. Similar results have also been found in other studies, for instance in a survey of school teachers' engagement in computational thinking practices [9].

Overall, teachers seem to be least confident with regard to competences related to programming and copyright/licenses. Sixty percent of the respondents felt very insecure (CSE 1-3) when it came to solving problems using programming. Similar results have been found elsewhere, for instance in England, where the new subject 
Computing was introduced in the curriculum in 2014. At that point, $60 \%$ of the teachers felt that they were not ready for teaching the new content [23]. In a report from 2017 [18], $48 \%$ of the teachers participating in a survey still were not confident in teaching Computing, due to, for instance, lacking "theoretical and technical knowledge of computing", including aspects of programming.

The large spread becomes particularly obvious when looking at the situation for low, moderate and strong self-efficacy respectively (Table 2 and Figure 4). Teachers with a strong self-efficacy had a CSE of 6 or 7 on almost all competences. The only exceptions were the competences related to digital traces, creative commons, programming and digital protection, which all had a CSE of 5 . Nevertheless teachers with a strong self-efficacy feel quite or very confident in all competence areas. For teachers with a moderate self-efficacy three competences were rated as strong (CSE of 6-7), while most competences fell in the moderate interval (CSE of 4-5). The competences where the respondents felt most insecure (CSE of 3) were the same as those for the respondents with a strong self-efficacy mentioned above (digital traces, creative commons, programming and protection from undesired access) in addition to using technology as a means of constructing a product. Finally, teachers with a low self-efficacy did not have a strong self-efficacy score for any competence. A minority of the competences $(7 / 27)$ had a moderate score (all competences in the first competence area, recognizing hate speech and summarizing information from different sources), but for the majority of the competences (20/27), teachers were quite insecure (CSE of 2-3).

Clearly, and unsurprisingly, this large spread shows that a onesize fits all teacher training approach is not appropriate, as the needs of teachers with low, moderate and strong self-efficacy are very different. When considering teachers with a low self-efficacy, support and guidance is needed in all competence areas except for the first one. Common to all teachers is a need for guidance in programming, licensing (creative commons) and security (protecting digital devices, managing digital traces). Luckily, quite some effort in teacher training initiatives is currently being invested in developing programming competence, which will hopefully strengthen teachers' confidence in this area. For creative commons, on the other hand, it seems that many teachers simply had no idea of what creative commons stands for and therefore rated their self-efficacy low on that particular competence. This is easily remedied by a short introduction to creative commons and how to use it when referring to other people's work as well as when sharing one's own material. Security issues, particularly when it comes to integrity aspects, have most likely not been taught previously, and these are also areas where many struggle as individuals in their everyday lives. This is hence an area, which calls for more focus in teacher training efforts.

The data analysed in our previous study were most likely not representative of the general teacher community, as the responses were collected through social media and emailing lists focusing on teachers currently enrolled in programming courses or those belonging to specific online interest groups related to digital competence and technology. In the current study, the data were collected during teacher training events, but these were voluntary and were marketed with a clear focus on digitalization and digital competence. Nevertheless, the results are much more diverse and appear to be more representative. One can, however, wonder whether the spread would be even larger in a more extensive and generalizable study setting. As there is still a lack of previous research on teachers' self-efficacy in the area of digital competence, there is not a significant body of empirical data, with which to compare our results. Instead, we advance the results presented in this study as a baseline for further studies and more detailed research. For instance, in Sweden, the National Agency for Education (Skolverket) is rolling out online courses on programming, offering professional development conferences throughout the country and giving universities the task to develop and offer courses aimed at teachers. Similarly, there is a need for teacher training departments to revise their curricula in order to prepare pre-service teachers for teaching digital competence. Using the same instrument to follow up on competence levels, makes it easier for both individuals, organisations and policy makers to evaluate the results of given initiatives as well as decide on what to focus on next.

Finally, respondents with a strong CSE level rated themselves very high (7) on the final competence ("I could adapt my ways of working based on new digital tools"). This competence can be seen as one of the most important ones on the list from a life-long learning perspective; in a situation where technology develops and changes at a fast pace, being able to adapt is crucial. Respondents with low self-efficacy, however, also rated themselves low (3) on this particular competence. Previous studies have indicated that teachers perceive knowledge and attitudes as critical precursors to creating a digitally competent school [8]. Training efforts should henceforth not only focus on helping teachers develop their digital knowledge and skills. Attitudes and mindset are likely to be equally important, and deserve more attention and educational investment.

\section{CONCLUSIONS}

Teacher self efficacy in digital competence and computational concepts is crucial to providing young people with the education they will require in our increasingly technological society. Schools and governments must take the need for continuing education in this area very seriously if we are to meet the challenges identified in this study. The results presented here imply strongly that helping teachers develop their self-efficacy in digital competences is important, as studies show that teachers with a high self-efficacy in the subject they teach are more likely to persist longer, provide a better teaching environment and not burn out as easily [24].

The study also provides some of the underpinnings crucial to addressing future in-service and pre-service teacher training and educational challenges. In particular we have identified some key areas which will require explicit attention. The results presented in this paper can also serve as a baseline for monitoring the development of teachers' self-efficacy over time as well as after particular training efforts. Results from this kind of studies naturally also lend themselves to be compared, thereby providing insight into teachers' self-efficacy in digital competences at a local (school/municipality), national or international level, as well as providing the opportunity to explore the development of instructional capability and capacity over time. 


\section{REFERENCES}

[1] Albert Bandura. 1977. Self-Efficacy: Toward a Unifying Theory of Behavioral Change. Psychological Review 84, 2 (March 1977), 191-215. http://www.eric.ed. gov/ERICWebPortal/detail?accno=EJ161632

[2] Albert Bandura. 1997. Self-efficacy: The exercise of control. Macmillan.

[3] Vehbi Celik and Etem Yesilyurt. 2013. Attitudes to technology, perceived computer self-efficacy and computer anxiety as predictors of computer supported education Computers \& Education 60, 1 (2013), 148 - 158. DOI : http://dx.doi.org/10.1016/j. compedu.2012.06.008

[4] EU Commission. Digital Competence Framework for Educators (DigCompEdu) https://ec.europa.eu/jrc/sites/jrcsh/files/digcompedu_leaflet_final.pdf. (????). Online, accessed April 22, 2017.

[5] Deborah R. Compeau and Christopher A. Higgins. 1995. Computer Self-Efficacy: Development of a Measure and Initial Test. MIS Quarterly 19, 2 (1995), 189-211. http://www.jstor.org/stable/249688

[6] P Eachus and S Cassidy. 1999. Developing the computer self-efficacy (CSE) scale: Investigating the relationship between CSE, gender and experience with computers. Retrieved April 24 (1999), 1999.

[7] Mavra Kear. 2000. Concept analysis of self-efficacy. Graduate research in nursing 2, 2 (2000), 1-7.

[8] Linda Mannila. 2018. Digitally competent schools: teacher expectations when introducing digital competence in Finnish basic education. Seminar.net (June 2018).

[9] Linda Mannila, Valentina Dagiene, Barbara Demo, Natasa Grgurina, Claudio Mirolo, Lennart Rolandsson, and Amber Settle. 2014. Computational Thinking in K-9 Education. In Proceedings of the Working Group Reports of the 2014 on Innovation \&\#38; Technology in Computer Science Education Conference (ITiCSE-WGR '14). ACM, New York, NY, USA, 1-29. DOI : http://dx.doi.org/10.1145/2713609.2713610

[10] Howard Margolis and Patrick P. McCabe. 2004. Self-Efficacy: A Key to Improving the Motivation of Struggling Learners. The Clearing House 77, 6 (2004), pp. 241-249. http://www.jstor.org/stable/30190019

[11] William P Moore and Mary E Esselman. 1994. Exploring the Context of Teacher Efficacy: The Role of Achievement and Climate. (1994).

[12] Christine A. Murphy, Delphine Coover, and Steven V. Owen. 1989. Development and Validation of the Computer Self-Efficacy Scale. Educational and Psychological Measurement 49, 4 (1989), 893-899. DOI : http://dx.doi.org/10.1177/ 001316448904900412

[13] Lars-Åke Nordén, Linda Mannila, and Arnold Pears. 2017. Development of a self-efficacy scale for digital competences in schools. In 2017 IEEE Frontiers in Education Conference (FIE)

[14] Arnold Pears, Valentina Dagiene, and Egle Jasute. 2017. Baltic and Nordic K-12 Teacher Perspectives on Computational Thinking and Computing. In International Conference on Informatics in Schools: Situation, Evolution, and Perspectives.
Springer, $141-152$.

[15] Vennila Ramalingam, Deborah LaBelle, and Susan Wiedenbeck. 2004. Self-efficacy and Mental Models in Learning to Program. SIGCSE Bull. 36, 3 (June 2004), 171175. DOI : http://dx.doi.org/10.1145/1026487.1008042

[16] Vennila Ramalingam and Susan Wiedenbeck. 1998. Development and Validation of Scores on a Computer Programming Self-Efficacy Scale and Group Analyses of Novice Programmer Self-Efficacy. Journal of Educational Computing Research 19, 4 (1998), 367-381. DOI : http://dx.doi.org/10.2190/C670-Y3C8-LTJ1-CT3P

[17] John A Ross, Anne Hogaboam-Gray, and Lynne Hannay. 2001. Effects of teacher efficacy on computer skills and computer cognitions of Canadian students in grades K-3. The Elementary School fournal 102, 2 (2001), 141-156.

[18] The Royal Society. 2017. After the reboot: computing education in UK schools. (2017).

[19] Erik E.J. Thoonen, Peter J.C. Sleegers, Thea T.D. Peetsma, and Frans J. Oort. 2011. Can teachers motivate students to learn? Educational Studies 37, 3 (2011), 345-360. DOI : http://dx.doi.org/10.1080/03055698.2010.507008

[20] Megan Tschannen-Moran and Anita Woolfolk Hoy. 2001. Teacher efficacy: Capturing an elusive construct. Teaching and teacher education 17, 7 (2001), 783-805.

[21] Vehbi1 Turel. 2014. TEACHERS' COMPUTER SELF-EFFICACY AND THEIR USE OF EDUCATIONAL TECHNOLOGY. Turkish Online fournal of Distance Education (TOfDE) 15, 4 (2014), 130 - 149. http://search.ebscohost.com.ezproxy. its.uu.se/login. aspx?direct $=$ true $\& \mathrm{db}=$ eue $\& A N=98889729 \&$ site $=$ ehost-live

[22] Ellen L. Usher and Frank Pajares. 2008. Self-Efficacy for Self-Regulated Learning. Educational and Psychological Measurement 68, 3 (2008), 443-463. DOI : http: //dx.doi.org/10.1177/0013164407308475

[23] YouGov. 2015. TES \& Nesta Computing Curriculum. Fieldwork 06/05/2014 16/05/2014. (2015)

[24] Marjolein Zee and Helma M. Y. Koomen. 2016. Teacher Self-Efficacy and Its Effects on Classroom Processes, Student Academic Adjustment, and Teacher Well-Being: A Synthesis of 40 Years of Research. Review of Educational Research 86, 4 (2016), 981-1015.

[25] Yixin Zhang and Sue Espinoza. 1998. Relationships among computer selfefficacy, attitudes toward computers, and desirability of learning computing skills. Fournal of Research on Computing in Education 30, 4 (Summer 1998), 420. http://ezproxy.its.uu.se/login?url=http://search.proquest.com.ezproxy.its. uu.se/docview/274681936? accountid=14715 Copyright - Copyright International Society for Technology in Education Summer 1998; Last updated - 2014-05-21.

[26] Barry J. Zimmerman. 2000. Self-Efficacy: An Essential Motive to Learn. Contemporary Educational Psychology 25, 1 (2000), 82 - 91. DOI : http://dx.doi.org/10. 1006/ceps.1999.1016

[27] Barry J Zimmerman and Albert Bandura. 1995. Self-efficacy and educational development. Self-efficacy in changing societies (1995), 202-231. 